\title{
POTENSI EKOSISTEM HUTAN MANGROVE TERHADAP KEBERADAAN MADU HUTAN SEBAGAI JASA LINGKUNGAN DI DESA BATU AMPAR KABUPATEN KUBU RAYA
}

\author{
(Potential Role Of Mangrove Forest Ecosystem Of Forest Honey In The Presence Of \\ Environmental Services In Batu Ampar Village Kubu Raya District)
}

\author{
Orind K Sihotang, Gusti Hardiansyah, Evy Wardenaar \\ Fakultas Kehutanan Universitas Tanjungpura Pontianak. J1. Daya Nasional Pontianak 78124 \\ E-mail : orindsihotang@gmail.com
}

\begin{abstract}
Mangrove forest ecosystem is a place to live living things and plants that live in the tidal area of the sea. For coastal communities the presence of mangrove honey is very beneficial, especially for fishermen. Because mangrove forests are their place of livelihood, one of them is forest honey which can increase their economic growth. Not only that mangrove forests provide a lot of environmental services that can play an important role in their survival as well as the environment around them and have a considerable impact on the current climate conditions of the world. The research aims to see how the potential of the mangrove ecosystem towards the existence of forest bees. As well as the availability of feed or flower extract nectar in the mangrove forest area that is needed as forest bee food and the value of benefits for forest honey farmers to the presence of forest bees (Apis Dorsata) in Batu Ampar Village, Kubu Raya Regency. This study uses a survey method by looking directly at the honeycomb attached to each tree. The results showed that the relative frequency of mangrove forests was $100 \%$. For the relative abundance obtained at 17\% while the actual dominance is $100 \%$ with INP 2.17 . While the total benefit value is Rp.476,141,924 with moderate levels of diversity. Mangrove forests provide the role of ecosystems in the presence of forest bees (Apis dorsata) in attaching their nests to nyiri trees (Xylocarpus granitus). For bee feed is found in nipah (Nypa) which has complete flowes are on the nypa has full flower.
\end{abstract}

Keywords: Forest Bee, Mangrove Ecosystem,

\section{PENDAHULUAN}

Indonesia memiliki hutan yang didalamnya terdapat banyak keanekaragaman hayati yang dimulai banyaknya flora dan fauna. Hal inilah yang membuat banyak pihak asing tertarik untuk melakukan penelitian akan kekayaan alam kita.

Hutan Indonesia terkenal sebagai hutan hujan tropis, hutan yang secara umum dikenal sebagai hutan lebat. Indonesia memiliki hutan yang sangat beragam jenisnya, mulai dari hutan primer hingga hutan mangrove. Hutan indonesia memiliki hasil alam yang berupa hasil hutan kayu yang dapat dijadikan sebagai bahan industri kayu, pulp, dan sebagainya. Selain hasil hutan berupa kayu Indonesia juga memiliki hasil hutan bukan kayu seperti rotan, kantong semar, madu hutan dan sebagainya.

Sistem pengelolaan lahan hutan yang direncanakan oleh pemerintah ditujukan untuk pemberdayaan masyarakat dengan berasaskan 
kelestarian hasil hutan dari aspek ekosistem, kesejahteraan masyarakat yang berkelanjutan, pengelolaan sumberdaya alam yang demokratis, keadilan sosial, akuntabilitas publik serta kepastian hukum. Hutan mangrove merupakan tempat yang memiliki fungsi sebagai pencegah abrasi pantai,menjaga kelestarian alam flora dan fauna, sebagai bahan baku penyedia obatobatan dan lain sebagainya. Oleh karena itu perlu upaya maksimal didalam mencegah kerusakan ekosistem hutan mangrove.

Luas hutan mangrove di Kabupaten Kubu Raya seluas 55.439 hektar(31\% dari seluruh luas daerah Kubu Raya sebesar 6.985,24 $\mathrm{KM}^{2}$ ). Sebagian yaitu 7\% (3.981 Ha) hutan mangrove tersebut berada di Desa Kuala Karang, Kecamatan Teluk Pakedai dalam kondisi rusak berat, dan $1 \%(561 \mathrm{Ha})$ rusak ringan akibat konversi, antara lain 0,5\%(300 Ha) hutan mangrove dengan status hutan lindung dikonversi menjadi tambak udang. (Dinas Kehutanan Kabupaten Kubu Raya,2010). Menurut data rekapitulasi, (Dinas Kehutanan Kabupaten Kubu Raya,2013), Hutan mangrove di Kubu Raya saat ini mempunyai luasan dengan kawasan hutan lindungnya sebesar 51.548,49 Ha, kawasan HPT seluas $32.370 \mathrm{Ha}$, kawasan HP seluas 1.097.00 dan kawasan APL seluas 13.336 Ha.

Bagi masyarakat pesisir pantai keberadaan madu hutan mangrove sangat menguntungkan terutama bagi para nelayan. Karena hutan mangrove merupakan tempat mata pencaharian mereka salah satunya madu hutan yang dapat meningkatkan pertumbuhan ekonomi mereka. Tidak hanya itu hutan mangrove menyediakan banyak sekali jasa lingkungan yang dapat berperan penting terhadap keberlangsungan hidup mereka dan juga lingkungan yang ada disekitarnya serta memberikan dampak pengaruh yang cukup besar terhadap kondisi iklim dunia saat ini.

Peran ekosistem juga penting bagi kawasan hutan mangrove untuk menjaga ekosistem yang ada didalamnya agar keberadaan hutan mangrove boleh terus ada serta perlu juga upaya meningkatkan kawasan hutan mangrove menjadi kawasan pelestarian alam. Oleh karena itu perlu adanya suatu kegiatan penanaman dan pemeliharaan yang bermanfaat serta pengetahuan tentang pengelolaan hutan mangrove agar terhindar dari pengrusakan. Penelitian bertujuan untuk melihat keadaan dilapangan bagaimana peran ekosistem mangrove terhadap keberadaan lebah hutan. Serta ketersediaan pakan atau nektar sari bunga yang ada di kawasan hutan mangrove yang dibutuhkan sebagai makanan lebah hutan. Untuk menghasilkan madu hutan di kawasan hutan mangrove di Desa Batu Ampar Kabupaten Kubu Raya serta nilai manfaat bagi para petani madu hutan terhadap keberadaan lebah hutan (Apis Dorsata).

\section{METODE PENELITIAN}

Penelitian ini dilaksanakan diareal hutan mangrove Desa Batu Ampar Kecamatan Batu Ampar kabupaten 
Kubu Raya yang dilakukan selama \pm 1bulan dilapangan. Peralatan yang digunakan meliputi: Kamera, alat tulis menulis, kuisioner, kalkulator, dan GPS.

Penelitian ini menggunakan metode survey dan wawancara. Data yang dikumpulkan ,disusun, dan kemudian dianalisis. Untuk memperoleh dan mengumpulkan data yang berhubungan dengan penelitian ini dilakukan dengan metode titik hitung.

Jenis data yang dikumpulkan dalam penelitian ada dua yakni data primer dan data sekunder. Data primer didapatkan dari hasil obervasi lapangan dan wawancara antara lain:

1. Jumlah sarang lebah dikawasan hutan mangrove.

2. Jenis vegetasi yang dijadikan sarang lebah.

3. Jenis vegetasi berbunga di kawasan hutan mangrove.

4. Pemafaatan madu hutan sebagai jasa lingkungan hutan mangrove.

Pengumpulan data sekunder (laporan, gambar, perizinan, dan peta) dilakukan dengan mendatangi beberapa instansi atau lembaga terkait.

Untuk mengetahui jumlah sarang dan vegetasi yang dijadikan tempat sarang mengunakan menggunakan metode titik hitung. Untuk mengetahui pemanfaatan madu hutan dilakukan dengan wawancara. Untuk pengolahan data seluruh manfaat dapat dilakukan seperti berikut:

Sesuai dengan tujuan penelitian analisa data dilakukan terlebih dahulu dengan mentabulasi data sebagai

berikut:

1. Frekuensi relatif

$\mathrm{Fr}=$ fix $100 \%$

$f i=$

Jumlah petak contoh yang mengandung jenis ke - i jumlah total petak contoh

2. Kelimpahan relatif

$\mathrm{Kr}=\frac{K i}{\sum k} \times 100 \%$

$K i=\frac{\text { Jumlah individu ke }-\mathrm{i} \text { disetiap habitat }}{\text { luas point } \mathrm{x} \text { total point disetiap habitat }}$

3. Uji Hutchinson

$$
\begin{aligned}
& \mathrm{thit}=\frac{H 1^{\prime}-H 2^{\prime}}{\sqrt{\text { VarH } 1+\operatorname{VarH} 2}} \\
& \mathrm{Db}=\frac{\left(\text { VarH } 1^{\prime}-\operatorname{Var} H 2^{\prime}\right) 2}{\left(\frac{\text { VarH1 }}{N 1}\right) 2+\left(\frac{\text { VarH2 }^{\prime}}{N 2}\right) 2} \\
& \text { Var } \mathrm{H}=\frac{\frac{\sum P i(\text { Inpi })^{2}-\left(\sum P i \text { Inpi }\right)^{2}}{N} \pm \frac{S-1}{2 \mathrm{~N}^{2}}}{\text { Keterangan : }} \\
& \mathrm{N}: \text { Jumlah total individu }
\end{aligned}
$$

seluruh jenis pada plot contoh

$\mathrm{H} \quad$ : Indeks

keanekaragaman

Pi : Proporsi nilai penting

$\ln$ : Logaritma natural

$S$ : Jumlah jenis

\section{Nilai Ekonomi Sumberdaya}

Mangrove

Penilaian manfaat ekonomi dari ekosistem hutan mangrove meliputi penilaian terhadap nilai kegunaan, nilai pilihan, nilai keberadaan. Penilaian total didapatkan dengan menjumlahkan semua nilai kegunaan, pilihan dan keberadaan.

1. Manfaat langsung

Nilai manfaat langsung merupakan pendapatan yang diperoleh dari produktivitas manfaat langsung setelah dikalikan harga pasar dan dikurangi biaya ekstraksi menurut Suparmoko et al in Saprudin, 2012. Tahap perhitungan untuk memperoleh nilai hasil/jasa hutan 
yang mempunyai nilai kegunaan pertahun. Tabel penilaian nilai manfaat langsung terjadi dalam Tabel 1 dan Tabel 2.

a. Nilai hasil hutan

1) Menghitung jumlah pungutan pertahun masing-masing hasil hutan setiap pemungut.
2) Mengalikan jumlah pungutan pertahun setiap pemungut dengan nilai atau harga perunitnya.

3) Mengalikan jumlah pungutan perorang dengan luas kawasan hutan mangrove.

4) Menjumlahkan nilai-nilai manfaat kawasan.

Tabel 1. Perkiraan Nilai Hasil Hutan Mangrove (Estimated Value Of Mangrove Forest Products)

\begin{tabular}{lllll}
\hline No & $\begin{array}{l}\text { Jenis Hasil } \\
\text { Hutan }\end{array}$ & $\begin{array}{l}\text { Nilai Rata- } \\
\text { rata/Orang }(\mathrm{Rp} / \mathrm{Th})\end{array}$ & $\begin{array}{l}\text { Nilai Rata-Rata } \\
\text { Kawasan } \\
(\mathrm{Rp} / \mathrm{Th})\end{array}$ & $\begin{array}{l}\text { Persentase } \\
(\%)\end{array}$ \\
\hline $\mathbf{1}$ & & & \\
$\mathbf{2}$ & & & \\
\hline
\end{tabular}

b. Jasa Hutan

Menghitung nilai subsitusi maka didekati dari harga barang/jasa subsitusinya.

Tabel 2. Perkiraan Nilai Jasa Hutan Mangrove (Estimated Value Of Mangrove Forest Services)

\begin{tabular}{lll}
\hline No Jenis Jasa Hutan & $\begin{array}{l}\text { Nilai Manfaat } \\
(\mathrm{Rp} / \mathrm{Th})\end{array}$ & $\begin{array}{l}\text { Persentase } \\
(\%)\end{array}$ \\
\hline 1 & &
\end{tabular}

2

Dst

c. Nilai Manfaat Pilihan

Nilai manfaat pilihan atau Option

Value (OV) adalah suatu nilai yang menunjukkan kesediaan seseorang untuk membayar terhadap suatu komoditi lingkungan untuk melestarikan hutan mangrove dimasa yang akan datang. Nilai manfaat pilihan didekati dengan mengacu pada nilai keanekaragaman hayati (biodiversity) hutan mangrove Indonesia yaitu US \$ $1.500 / \mathrm{km} 2 /$ tahun. Nilai ini dapat dipakai untuk hutan mangrove diberbagai daerah di Indonesia apabila ekosistem hutan mangrovenya secara ekologis penting dan tetap terpelihara secara alami.

$\mathrm{MP}=\mathrm{MPBi}$

Keterangan:

MP = Manfaat pilihan

MPBi = Manfaat pilihan biodiversity

d. Nilai Manfaat Keberadaan

Manfaat keberadaan atau Existence Value (EV) adalah manfaat yang dirasakan oleh masyarakat dari keberadaan mangrove setelah manfaat lainnya dihilangkan dari analisis sehingga nilainya merupakan nilai ekonomis keberadaan suatu komponen ekosistem. Dari hasil wawancara yang diperoleh, nilai keberadaan hasil hutan berdasarkan 
kesediaan responden untuk membayar

dilihat pada Tabel 3.

terhadap komoditi lingkungan dapat

Tabel 3. Kompilasi Nilai Keberadaan Hutan Mangrove (Compilation Of The Value Of The Presence Of Mangrove Forests)

\begin{tabular}{|c|c|c|c|c|c|}
\hline No & $\begin{array}{l}\text { Tingkat } \\
\text { Pendidikan }\end{array}$ & $\begin{array}{l}\text { Nilai } \\
\text { (Rp) }\end{array}$ & Valuasi & Responden & Nilai (Rp) \\
\hline \multirow[t]{2}{*}{1} & Tidak Sekolah & & & & \\
\hline & Rata - rata & & & & \\
\hline \multirow[t]{2}{*}{2} & SD & & & & \\
\hline & Rata - rata & & & & \\
\hline \multirow[t]{2}{*}{3} & SMP & & & & \\
\hline & Rata - rata & & & & \\
\hline \multirow[t]{2}{*}{4} & SMA & & & & \\
\hline & Rata - rata & & & & \\
\hline
\end{tabular}

Setelah semua data pemanfaatan telah dikuantifikasikan, selanjutnya pengolahan data untuk Nilai Ekonomi Total hutan mangrove dilakukan dengan cara menjumlahkan semua nilai manfaat yaitu nilai manfaat langsung, manfaat tidak langsung, manfaat pilihan dan manfaat keberdaan, sehingga nilai ekonomi total dapat diformulasikan sebagai berikut (Fitriani, 2012 inAbner et al, 2014):

NET $=$ ML + MP + MK

Keterangan:

NET $=$ Nilai ekonomi total

ML = Manfaat Langsung
MP = Manfaat Pilihan

MK = Manfaat Keberadaan

\section{HASIL DAN PEMBAHASAN}

Potensi Hutan Mangroves

Berdasarkan hasil observasi yang dilakukan di Areal hutan mangrove di Desa Batu Ampar dari masing-masing setiap titik plot pengamatan. Menurut Adriyanto Siombo et al (2014) mengatakan pakan lebah hutan pada kawasan hutan lindung terdapat pada pohon pulai (Alstonia scholaris) termasuk dalam famili Fagaceae dengan nilai INP paling tinggi sebesar $26,07 \%$. 


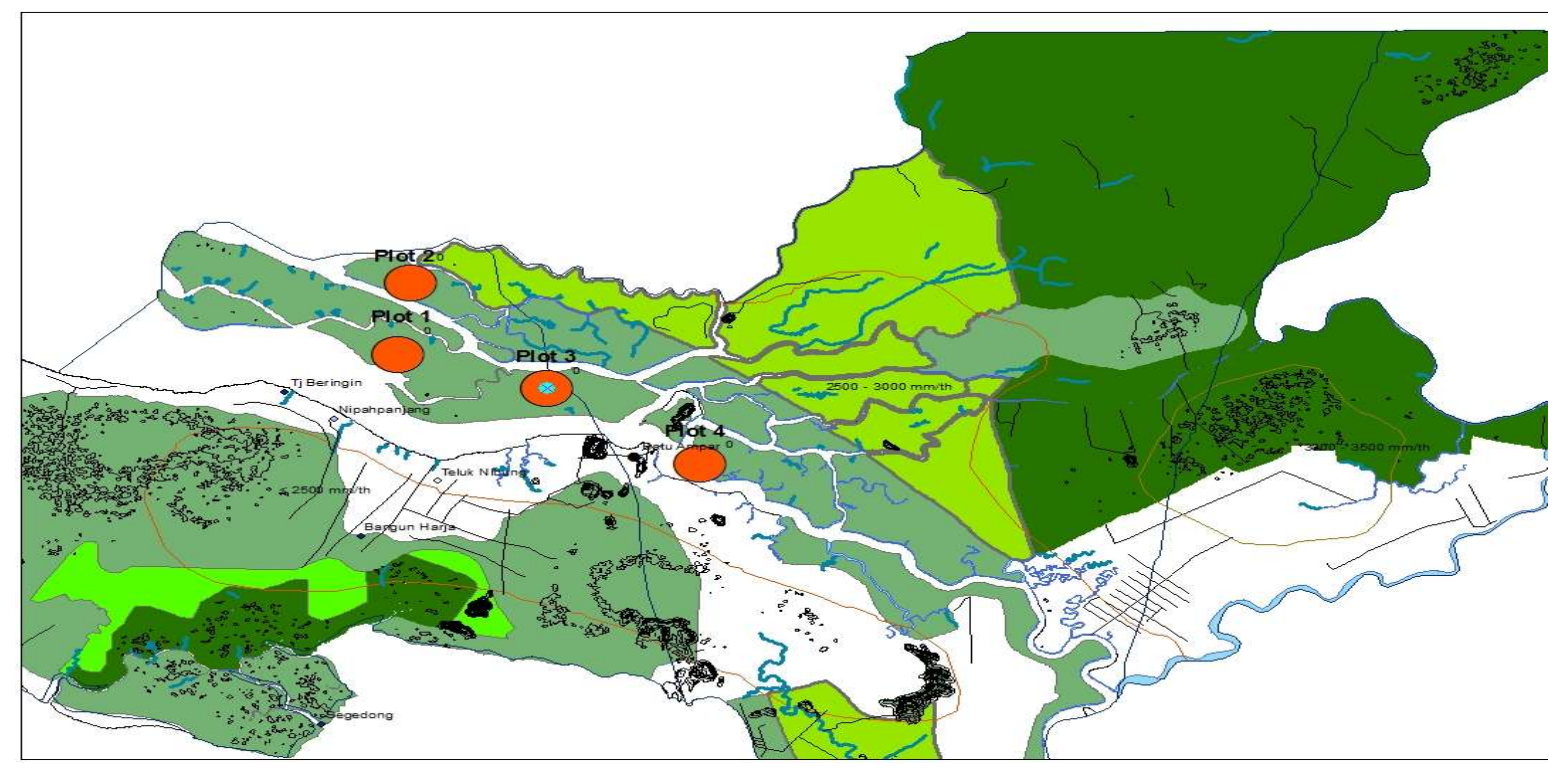

Gambar 1. Peta Plot Hutan Mangrove (Map of the Mangrove Forest Plot)

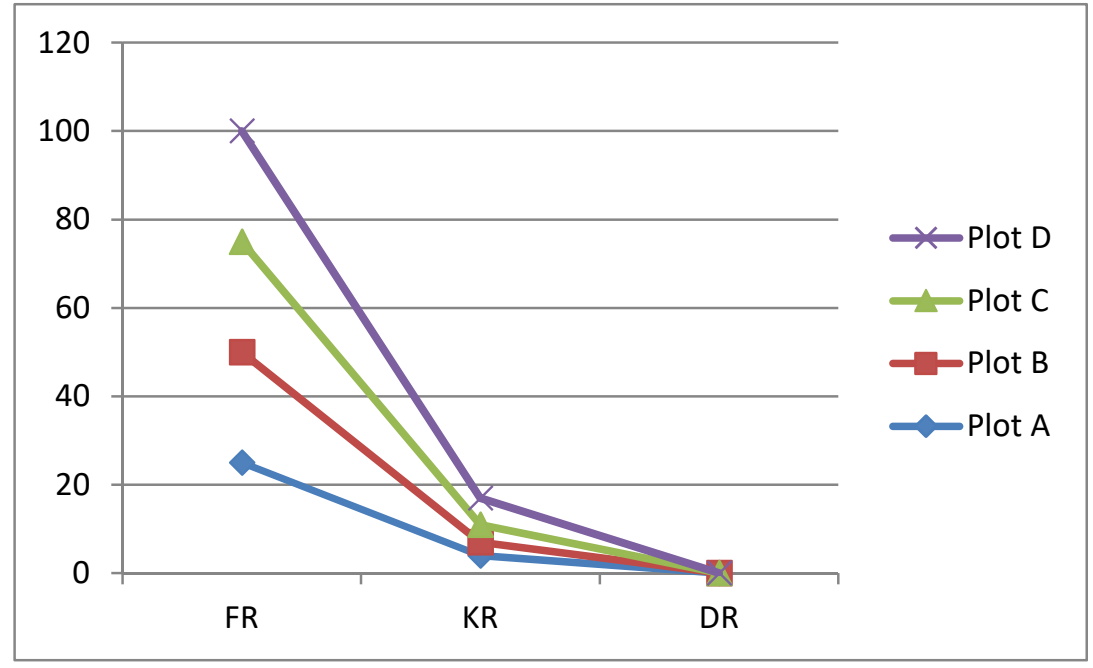

Gambar 2. Tingkat Kekayaan Jenis Hutan Mangrove (Level of Wealth of

Mangrove Forest Types)

Grafik pada gambar 2 menjelaskan pengaruh ekosistem yang dilihat dari tingkat frekuensi relatif, kelimpahan relatif, dan dominansi relatif. Hasil analisis vegetasi pada vegetasi pada gambar 2 menunjukkan bahwa lebah hutan (Apis dorsata) paling banyak menempelkan sarangnya pada pohon nyiri (Xylocarpus granitus) dengan frekuensi relatif (FR) sebesar 100\%, kelimpahan relatif( $\mathrm{KR}$ ) sebesar $17 \%$, dan dominansi relatif sebesar (DR) $100 \%$. 


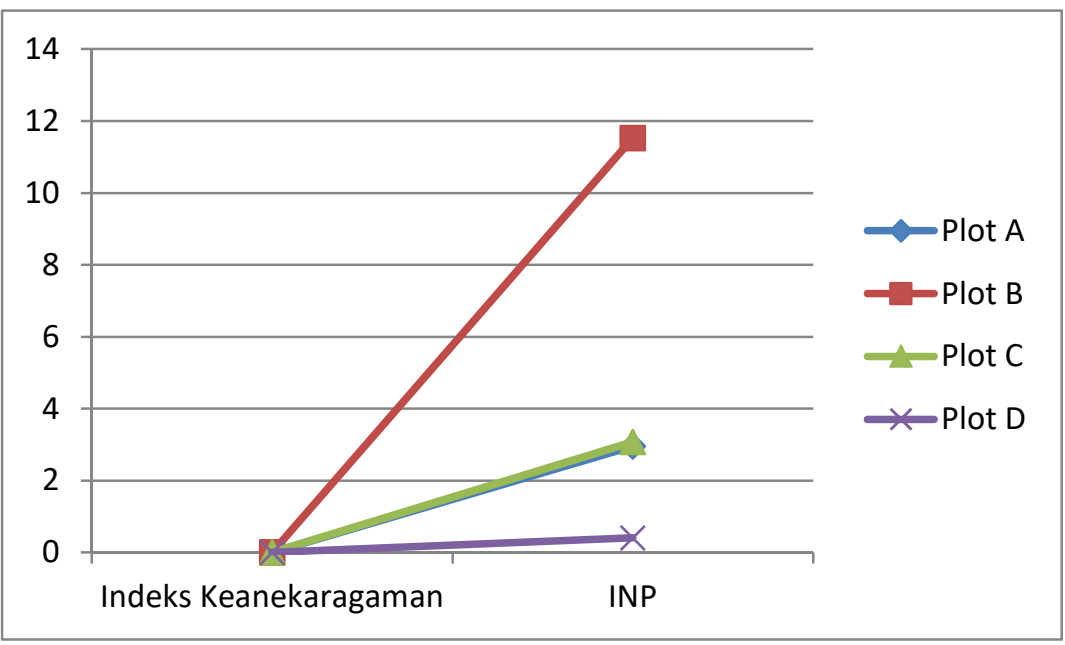

\section{Gambar 3. Nilai Indeks Kekayaan Jenis Hutan Mangrove ( Mangrove Forest Wealth Index Value)}

Nilai indeks penting (INP) dari mangrove didapatkan dari akumulasi nilai kelimpahan relatif dan frekuensi relatif menunjukkan peran mangrove dalam menjaga kelestarian lingkungan pesisir tergolong kategori sedang ( INP berkisar antara 1,06 - 2,04) menurut Romadhon (2008).

Dari hasil INP pada gambar 3 sebesar 2,17 artinya kawasan hutan mangrove memiliki potensi yang tinggi dari hasil penelitian sebelumnya yang termasuk kategori sedang. Hal ini dipengaruhi oleh banyaknya jenis pohon yang ditemui daam setiap pengamatan seperti pohon nyiri (Xylocarpus granitus), bakau (Rhizopora) api - api (Avicennia), dan nipah (Nypa).

Yanuar Et.al (2015) mengatakan indeks keanekaragaman mangrove menunjukkan secara keseluruhan mempunyai kriteria keanekaragaman jenis tergolong sedang $\left(\mathrm{H}^{\prime}=0,55-1,86\right)$. Menurut Soesilawati dan Kuntadi (2014) mengatakan faktor penyebab kegagalan pemanenan madu hutan yang ada di Danau Sentarum adalah menurunnya populasi koloni lebah hutan dan berkurangnya sumber pakan.

Hasil ini menunjukan potensi ekosistem mempengaruhi lebah hutan untuk membuat sarangnya. Jika peran ekosistem untuk pakan lebah tersedia dengan kondisi hutan mangrove yangmasih memiliki kerapatan cukup tebal maka bukan tidak mungkin sarang lebah akan banyak menempel pada pohon. Berdasarkan penelitian yang diketahui bahwa satu sarang lebah hutan dapat menghasilkan 1 sampai $3 \mathrm{~kg}$ madu tergantung besarnya sarang lebah hutan. Hasil jasa lingkungan yaitu madu hutan akan membawa pengaruh yang besar bagi masyarakat untuk melestarikan terus kawasan hutan mangrove.

\section{Nilai Ekonomi Sumber Daya Hutan}

\section{A. Jasa Hutan}

Nilai jasa hutan diperoleh dari pendapatan, keuntungan dan biaya pengganti yang diterima atau dikeluarkan oleh responden selama 
kegiatan pemanenan madu hutan. Menurut Fitriani (2014) mengatakan Kualitas madu secara umum ditentukan oleh jenis lebah, jenis makanan (nektar), tempat tumbuh, cuaca/iklim. Faktorfaktor yang menyebabkan madu murni tidak berkualitas: 1.Tempat lebah tumbuh dan berkembang biak. 2 . Teknik budi daya lebah yang kurang profesional. 3. Panen madu yang belum waktunya, 4. Pengolahan pasca panen. 5. Kualitas madu juga tergantung jenis bunga dan tumbuhan yang ada di sekitar sarang lebah penghasil madu.

Potensi madu hutan yg dimanfaatkan masyarakat Batu Ampar untuk 10 orang adalah sebesar Rp. 1.200.000,-. Nilai untuk jasa hutan mangrove yaitu madu hutan maka hasil yang didapatkan dalam setahun adalah Rp. 14.400.000,-. Untuk menuju ke lokasi menggunakan perahu dengan biaya beli premium sebesar Rp. 150.000. Nilai untuk jasa hutan mangrove adalah Rp. 14.400.000,- ini termasuk pendapatan bersih. Menurut Birgantoro, et.al ( 2007) mengatakan nilai manfaat madu hutan pada kawasan HTI yang dimanfaatkan masyarakat adalah sebesar Rp. 4.325.002,-. Dari hasil penelitian ini menunjukkan pendapatan masyarakat bertambah setelah adanya madu hutan.hasil tersebut sangat besar dibandingkan dengan penelitian yang sebelumnya.

B. Nilai Manfaat Pilihan

Nilai manfaat pilihan atau Option Value (OV) adalah suatu nilai yang menunjukkan kesediaan seseorang untuk membayar terhadap suatu komoditi lingkungan untuk melestarikan hutan mangrove dimasa yang akan datang. Nilai manfaat pilihan didekati dengan mengacu pada nilai keanekaragaman hayati (biodiversity) hutan mangrove Indonesia yaitu US\$ $1.500 / \mathrm{km} 2 /$ tahun atau US\$ $15 /$ ha/tahun. Dengan luas hutan mangrove $34.184 \mathrm{Ha}$ dan nilai tukar rupiah 26 Agustus 2016 dengan nilai jual sebesar Rp. 13.386. dan nilai beli 13.086. Sehingga nilai rata- rata nilai tukar rupiah Rp. 13.236. Nilai pilihan Hutan mangrove Batu Ampar adalah Rp. 452.459.424. Menurut Lilian (2009) nilai manfaat pilihan hutan mangrove Desa Tawiri saat ini sebesar Rp 138.000,00/ha/tahun dikalikan dengan luasan hutan mangrove 3,08 ha, maka diperoleh nilai manfaat sebesar Rp.457.587.024 /ha/tahun. Hasil ini termasuk besar bila dibandingkan penelitian sebelumnya yang luas kawasan 3,08 ha. Luas kawasan hutan mangrove di Desa Batu Ampar adalah 34.184 ha dapat dilihat pada gambar 4 peta luas kawasan hutan mangrove. Hal ini tergantung menjadi pengaruh bagaimana masyarakat berupaya dalam mengola ekosistem. Inilah modal yang harus dikeluarkan oleh masyarakat dalam upaya melestarikan ekosistem hutan mangrove khususnya di Desa Batu Ampar apalagi terdapat sarang madu hutan yang menjadi hasil pendapatan tambahan. 


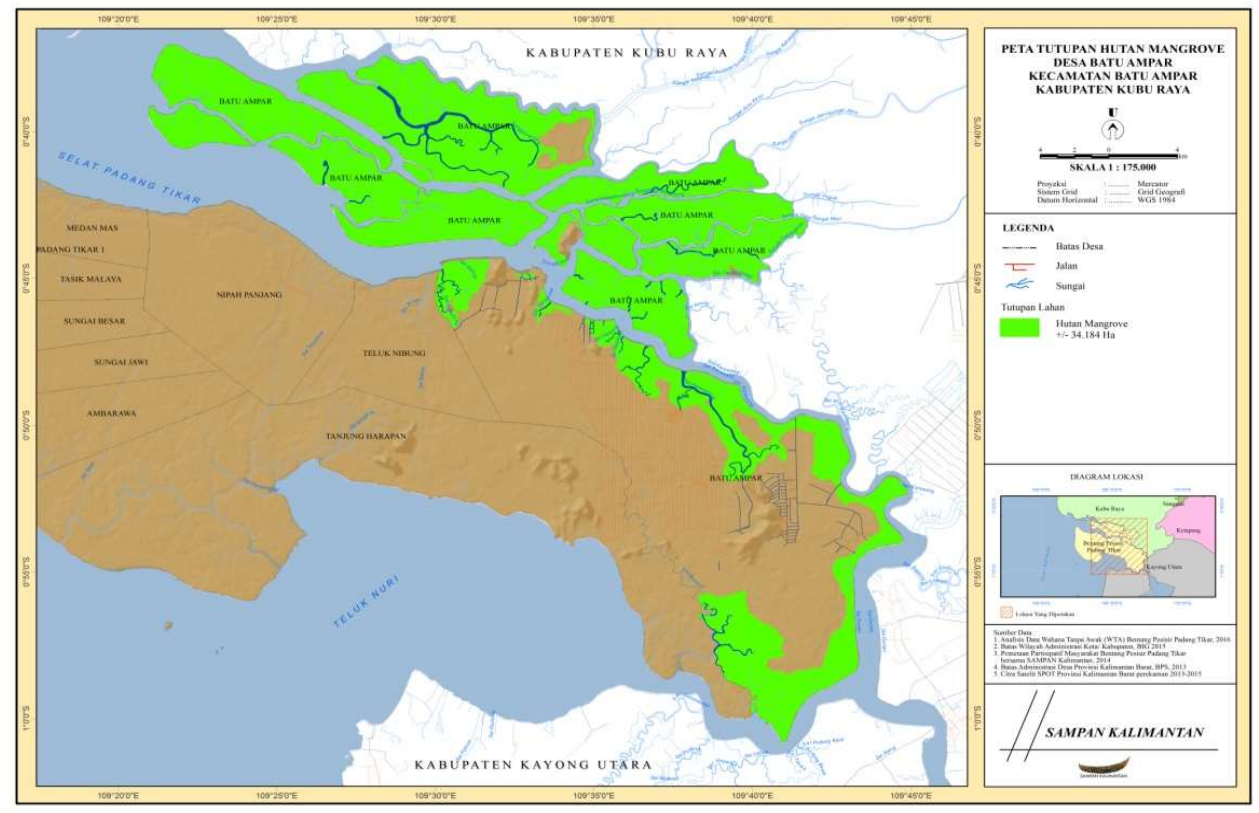

\section{Gambar 4. Peta Luas Kawasan Hutan Mangrove ( Map of Extent of} Mangrove Forest Area)

C. Nilai Manfaat Keberadaan

Manfaat keberadaan atau Existence Value (EV) adalah manfaat yang dirasakan oleh masyarakat dari keberadaan mangrove setelah manfaat lainnya dihilangkan dari analisis sehingga nilainya merupakan nilai ekonomis keberadaan suatu komponen ekosistem. Dari hasil wawancara yang diperoleh, nilai keberadaan hasil hutan berdasarkan kesediaan responden untuk membayar terhadap komoditi lingkungan dapat dilihat pada Tabel 4.

Tabel 4. Nilai Keberadaan Madu Hutan Mangrove (Value of Existence of Mangrove Forest Honey)

\begin{tabular}{llrrr}
\hline No & \multicolumn{1}{c}{$\begin{array}{c}\text { Tingkat } \\
\text { Pendidikan }\end{array}$} & $\begin{array}{c}\text { Nilai Pendapatan } \\
\text { (Rp) }\end{array}$ & Responden & Nilai (Rp) \\
\hline 1 & Tidak Sekolah & $50-100.000$ & & \\
& & $100.000-500.000$ & 1 & 500.000 \\
& & $>500.000$ & 4 & 4.077 .500 \\
& Rata - rata & $50.000-100.000$ & & \\
2 & SD & $100.000-500.000$ & & 3.577 .500 \\
& & $>500.000$ & 4 & 3.285 .000 \\
& & & & \\
& Rata - rata & $50.000-100.000$ & & 1.420 .000 \\
& SMP & $100.000-500.000$ & & \\
& & $>500.000$ & 1 & \\
& Rata - rata & & & 9.282 .500 \\
\hline
\end{tabular}


Menurut Desti dkk (2016) nilai manfaat keberadaan hutan mangrove yang dilakukan pada 50 responden, dapat diketahui bahwa nilai manfaat keberadaan sumberdaya mangrove adalah sebesar Rp.5.652.958,/ha/tahun. Hasil yang didapatkan dalam penelitian ini pada tabel 4 masih kecil karena tidak mencakup luas kawasan hanya mencakup tingkat pendapatan masyarakat. Kuisioner dilakukan hanya berfokus pada 10 orang nelayan yang pertama melakukan kegiatan pemanenan madu hutan di kawasan hutan mangrove Desa Batu Ampar. Hasil ini menunjukkan bagaimana peran madu hutan dalam meningkatkan taraf hidup para masyarakat yang memiliki pekerjaan utama sebagai nelayan dalam memanfaatkan akan suatu komoditas dari hutan mangrove.

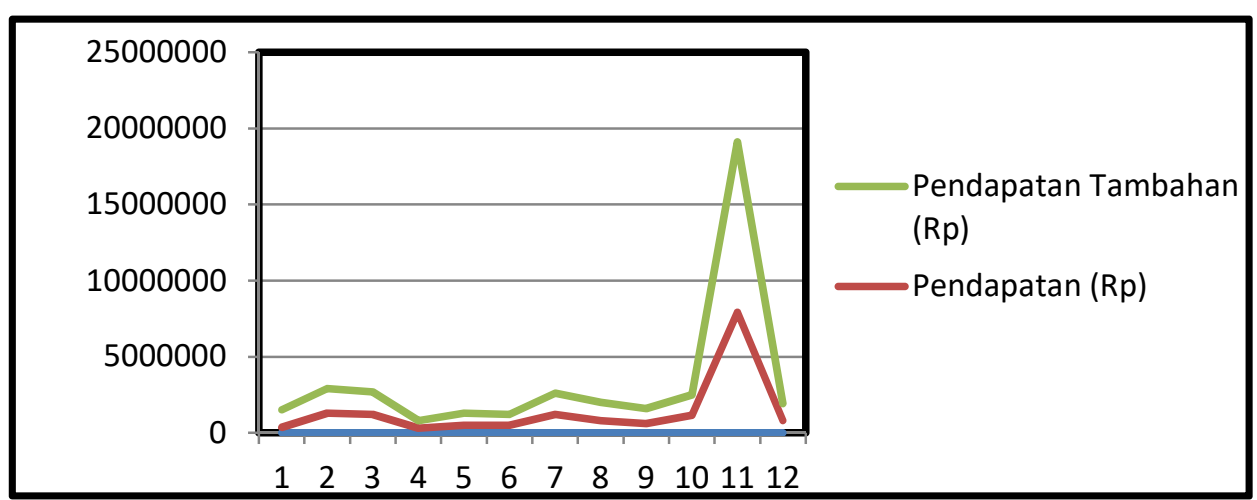

\section{Gambar 5. Tingkat Pengaruh Madu Hutan Sebagai Jasa Lingkungan ( Level of Effect of Forest Honey as Environmental Services)}

Grafik pada gambar 5 diatas bagaimana pengaruh ekosistem dalam menghasilkan jasa lingkungan yang memiliki komoditas nilai jual salah satunya adalah madu hutan yang menjadi pengaruh atau dampak langsung bagi masyarakat sekitar kawasan hutan mangrove di Desa Batu Ampar. Pada grafik tingkat yang tinggi dapat dijelaskan bahwa potensi ekosistem yang besar akan menghasilkan banyak jasa lingkungan yang dimanfaatkan bagi masyakat. Sebaliknya jika semakin rendah jasa lingkungan dari ekosistem hutan mangrove maka semakin kecil hasil yang didapatkan masyarakat. Itu tergantung bagaimana masyarakat di Desa Batu Ampar dalam melestarikan kawasan hutan mangrove.

Selanjutnya pengolahan data untuk Nilai Ekonomi Total hutan mangrove dilakukan dengan cara menjumlahkan semua nilai manfaat yaitu nilai manfaat langsung, manfaat pilihan dan manfaat keberadaan, sehingga nilai ekonomi total dapat diformulasikan sebagai berikut:

$$
\begin{aligned}
\text { NET } & =\mathbf{M L}+\mathbf{M P}+\mathbf{M K} \\
\mathrm{NET} & =14.400 .000+452.459 .424+9.282 .500 \\
& =476.141 .924
\end{aligned}
$$

Dari hasil perhitungan nilai manfaat dengan menjumlahkan antara manfaat 
langsung, manfaat pilihan dan manfaat keberadaan maka akan di dapatkan nilai ekonomi total sebesar Rp. 476.141.924,hasil nilai ekonomi total berasal dari semua penjumlahan nilai manfaat. Jadi nilai ekonomi total adalah nilai yang berperan terhadap masyarakat sekitar dalam memanfaatkan hasil pada kawasan hutan mangrove di Desa Batu Ampar.

\section{Pelestarian Hutan Mangrove}

Masyarakat pesisir, khususnya yang berkaitan dengan hutan mangrove secara turun temurun telah melaksanakan berbagai kegiatan dalam pemanfaatan Hutan Mangrove. Manfaat peran ekosistem sangatlah penting dalam menjaga kelestarian. secara tidak sadar masyarakat sudah merasakan nilai ekonomis terutama adanya madu hutan. Grafik pada gambar 7 menunjukkan pengaruh jasa lingkungan terhadap masyarakat. Jika jasa lingkungan dimanfaatkan dengan baik dengan konsep pelestarian lingkungan maka akan semakin banyak hasil yang didapatkan. Jika jasa lingkungan tidak dimanfaatkan dengan baik maka akan sedikit hasil yang didapatkan dan hutan makin lama akan mengalami kerusakan.

Manfaat lain adalah kehidupan flora dan fauna yang masih alami. Bukan tidak mungkin jika suatu saat Desa Batu Ampar dapat dijadikan lokasi wisata alam dengan konsep ekowisata. Dengan keberadaan madu hutan mangrove masyarakat megalami peningkatan taraf hidupnya. Dengan menjaga kawasan hutan secara baik dari illegal logging dan ancaman degradasi serta deforestasi. Maka hasil hutan yaitu madu hutan akan tetap tersedia. Untuk itulah masyarakat diharapkan untuk memanennya madu hutan dan hasil hutan lainnya secara lestari.

\section{Kesimpulan}

1. Hutan Mangrove Di Desa Batu Ampar merupakan kawasan Kabupaten Kubu Raya yang memiki vegetasi yang masih lestari. Hasil menunjukkan indeks nilai penting sebesar 2,17 dengan frekuensi relatif sebesar $100 \%$, kerapatan relatif sebesar $17 \%$ dan dominansi relatif sebesar $\quad 100 \%$. Indeks keanekargaman menunjukkan $\mathrm{H}^{\prime}<1$ artinya tingkat keanekaragaman sedang hal ini disebabkan hanya ada beberapa jenis tanaman yang berperan terhadap Lebah hutan.

2. Nilai manfaat yang terdiri dari jasa hutan terhadap keberadaan madu hutan sebesar Rp. 14.400.000, manfaat pilihan sebesar Rp. 457.587.024,- ha/tahun dan manfaat keberadaan sebesar Rp. 9.282.500,dengan nilai ekonomi total (NET) sebesar Rp. 476.141.924,--

3. Madu hutan merupakan jasa lingkungan untuk itu perlu upaya tetap menjaga peran hutan mangrove terhadap keberadaan lebah hutan dalam menghasil kan madu hutan. Kontribusi madu hutan memiliki peran yang baik dalam meningkatkan taraf hidup masyarakat Desa Batu Ampar. Untuk itu keberadaan madu hutan harus dapat dimanfaatkan sebaik mungkin disamping mata pencaharian utama. 


\section{Saran}

1. Perlu upaya tetap memanen madu hutan secara lestari. Agar keberadaan lebah hutan tetap membuat sarangnya sehingga madu yang dihasilkan cukup banyak.

2. Perlunya tetap menjaga hutan dari titik api yang dapat memicu kebakaran. Yang membuat keberadaan lebah hutan menjadi terganggu dan pergi untuk membuat sarang baru. Hal ini dikarenakan lebah hutan sangat sensitif terhadap adanya asap.

3. Hindari tambak ikan yang dapat menurunkan kualitas air yang berhubungan langsung dengan pohon yang ada hutan mangrove sehingga dapat merusak ekosistemnya secara perlahan.

\section{Daftar Pustaka}

Abner Widoyo M, Syukur U, Bau T. 2014. Nilai Manfaat Hutan Mangrove Di Desa Sausu Peore Kecamatan Sausu Kabupaten Parigi Moutong. Rimba Volume 2 No. 2. 92-101.

Adriyanto S, Elhayat L, Rahmawati. Keanekaragaman Jenis Pakan Lebah Hutan ( Apis spp) Di Kawasan Hutan Lindung Desa Ensa, Kecamatan Mori Atas, Kabupaten Morowali Utara. Warta Rimba Vol. 2 Nomor 2 Hal 49- 56. Desember 2014.

A. Mujetahid M. 2007. Teknik Pemanenan Lebah Hutan Oleh Masyarakat Sekitar Hutan Di Kecamatan Mallawa Kabupaten Marros. Perennial Volume 4, (1), 36-40.
Arief, Arifin. 2003. Hutan Mangrove Fungsi \& Manfaatnya.Yogyakarta:Kanisius.

Bakti Abu D, Dodik R Nurrohmat. Pemanfaatan Sumberdaya Hutan oleh Masyarakat di KPH Banyuwangi Utara. JMTH Vol. XIII(3): 172-181, Desember 2007.

Dahuri, R. 1996. Tipologi Ekosistem Pesisir dan Lautan Serta Tingkat Kerawanannya. Makalah Pada Kursus Penyusunan Analisis Mengenai Dampak Lingkungan XVIII, BAPEDAL dan PPSML LPUI, Jakarta.

Desty S, Supriharyono dan Imam T. Valuasi Ekonomi Sumberdaya Mangrove di Kelurahan Mangunharjo, Kecamatan Tugu, Kota Semarang. Saintek Perikanan Vol. 12 No. 1: 67-74, Agustus 2016

Dinas Kehutanan Kubu Raya.2013. Data Rekapitulasi Hutan Mangrove Kabupaten Kubu Raya. Kabupaten Kubu Raya.

Edi M, Okik H, dan Nur Fitriani (2010). Konservasi Hutan Mangrove Sebagai Ekowisata. Ilmiah Teknik Lingkungan 1: $51-57$.

Fachrul, M. F. 2007. Metode Sampling Bioekologi. Bumi Aksara. Jakarta.

Fitriani, Arfa A Rezekiah, Adistina F. Analisa Usaha Lebah Madu Hutan Dan Kualitasnya. Hutan Tropis, Vol 2 No.1, Maret 2014.

Hasmar R, 2009. Perbandingan Keanekaragaman Burung Pada Pagi Dan Sore Hari Di Empat Tipe Habitat Di Wilayah Pangandaran, Jawa Barat. Vis Vitalis, Vol. 02 No. 1, Maret 2009 
Heri S, 2013. Status Ekologi Hutan Mangrove Pada Berbagai Tingkat Ketebalan. Wallacea Vol. 2 No. 2, Juni 2013 : 104 - 120. Hutan Di Desa Ujung Jaya Kawasan Taman Nasional Ujung Kulon

Hermita N, 2013. Inventarisasi Tumbuhan Pakan Lebah. Agroekoteknologi Volume 6,(2),123-135.

Howes, J., D. Bakewell, \& Y.R. Noor. (2003). Panduan Studi Burung Pantai, Bogor:Wetlands International-Indonesia

Programme.

Kusmana, C., S. Wilarso, I. Hilwan, P. Pamoengkas, C. Wibowo, T Tiryana, A.Triswanto, Yunasfi, \& Hamzah. (2003). Teknik Rehabilitasi Mangrove. Bogor: Fakultas Kehutanan IPB.

Lilian S Haryani. Identifikasi Nilai Ekonomi Ekosistem Hutan Mangrove Di Desa Tawiri, Ambon. Organisasi Dan Manajemen Vol. 5 No. 1, Maret 2009:23-24.

Naamin, N, 1991. Penggunaan Hutan Mangrove Untuk Budidaya Tambak Keuntungan dan Kerugian. Prosiding Seminar IV Ekosistem Hutan Mangrove. MAB Indonesia-LIPI, Bandar Lampung.

Ponnambalam, K.Lakshuma C,Vivegarananda S.,Janathan M.P, 2012. Mangrove Distributio and Morphology Changes in the Multipallam Creek. SouthEastern Coast Of India. Internasional Journal of Conservation Siences.Volume 3,(1),51-66.
Romadhon A, 2008. Kajian Nilai Ekologi Melalui Inventarisi Dan Nilai Indeks Penting (INP) Mangrove Terhadap Perlindungan Lingkungan Kepulauan Kangean. Embryo. Vol 5 No.1 Hal 82 - 97. Juni 2008

Romimohtarto, K. 2001. Biologi Laut. Ilmu Pengetahuan tentang Biologi Laut. Penerbit Djambatan. Jakarta.

Sabaruddin R, 2013. Potensi Hutan Mangrove Sebagai Pelindung Pantai Terhadap Serangan Gelombang. Jurnal Teknik Perkapalan. Vol. 7: Desember 2013.

Saprudin, Halidah, 2012. Potensi Dan Nilai Manfaat Jasa Lingkungan Hutan Mangrove Di Kabupaten Sinjai Sulawesi Selatan. Penelitian Hutan dan Konservasi Alam. Vol. 9 No. 3 : 213-219, 2012.

Sarwo E Saputra, Agus S, 2014. Potensi Ekowisata Hutan Mangrove Di Desa Merak Belantung Kecamatan Kalianda Kabupaten Lampung Selatan. Sylva Lestari. Vol. 2, No. 2 : 49-60, 2014.

Soesilawati H, Kuntadi, 2014. Faktor Penyebab Kegagalan Panen Madu Hutan Di Taman Danau Sentarum Pada Musim Panen Tahun 2009 - 2012. Penelitian Hutan dan Konservasi Alam. Vol 11 No. 2. Hal. 171- 182. Agustus 2014.

Soetjipta, 1993. Dasar-dasar Ekologi Hewan. Depdikbud. Jakarta.

Supriharyono. 2000. Pelestarian dan pengelolaan Sumber Daya Alam di Wilayah Pesisir Tropis. 
Penerbit PT. Gramedia Pustaka Utama. Jakarta.

Suryani M, 2006. Ekologi Kepiting

Bakau (Scylla serrata Forskal)

Dalam Ekosistem Mangrove Di

Pulau Enggano Provinsi

Bengkulu. Tesis. Universitas

Diponegoro Semarang.

Susanna (2011). Valuasi Ekonomi Sumberdaya Hutan Mangrove Di Desa Palaes Kecamatan Likupang Barat Kabupaten Minahasa Utara. ASE Vol 7 No. 2 Hal. 29-38 2011 .

Wijayanti Tri, 2006. Konservasi Hutan Mangrove Sebagai Hutan Pendidikan. Teknik Lingkungan.Volume I Edisi Khusus.
Wibowo K dan Titin H, 2006. Pelestarian Hutan Mangrove Melalui Pendekatan Mina Hutan ( Silvofishery).

Teknik Lingkungan. Vol. 7 No. 5. Hal. 227-233.

Winda D Kalitouw, 2015. Valuasi Ekonomi Hutan Mangrove Di Desa Tiwoho Kecamatan Wori Kabupaten Minahasa Utara. Jurnal Penelitian 2015.

Yanuar R Buwono, .I.P.G. Ardhana, Made Sudarma (2015). Potensi Fauna Akuatik Ekosistem Hutan Mangrove Di Kawasan Teluk PangPang Kabupaten Bayuwangi. Ecotrophic Vol 9 (2). Hal. 28-33 